\title{
REPORTE CLINICO: HISTOPLASMOSIS DISEMINADA ALOCTONA EN UN PACIENTE CON SINDROME DE INMUNODEFICIENCIA ADQUIRIDA
}

\author{
(Clinical report:Disseminated allocthonous histoplasmosis in a acquired \\ immunodeficience syndrome patient)
}

\author{
*Rodrigo Cruz; **Héctor Opazo; *** Elizabeth Barthel; \\ ****Silvia Campos \& *Eduardo Piontelli \\ *Univ. de Valparaíso, Esc. de Medicina,Cátedra de Micología, Casilla 92 V Valparaíso, Chile. \\ **Univ. de Valparaíso, Esc. de Medicina, Cátedra de Anatomía Patológica, \\ *** Hospital Carlos van Buren, Unidad de Infectología, Valparaíso; \\ **** Hospital Eduardo Pereira, Servicio Medicina Interna, Valparaíso
}

Palabras clave: Histoplasma capsulatum, alóctono, SIDA, Chile.

Key words: Histoplasma capsulatum, allocthonous, AIDS, Chile.

\section{RESUMEN}

Se describe un caso de histoplamosis diseminada alóctona en un paciente con SIDA, de nacionalidad colombiana, quien ingresó al país en Marzo del 2006. Consultó por cuadro clínico de 2 meses de evolución, con dolor abdominal intenso, vómitos, baja de peso, diaforesis, fiebre vespertina, adenopatías múltiples y candidosis oral. De los exámenes destacó radiografía de tórax con infiltrado intersticial, pancitopenia, ELISA para VIH positivo y cultivos microbiológicos negativos. El paciente evolucionó desfavorablemente a pesar del tratamiento antimicrobiano empírico de amplio espectro; se tomó biopsia de ganglio cervical cuyo informe reveló presencia de levaduras gemantes en focos de necrosis, por lo que se inició tratamiento con anfotericina $B$ y se repitió la biopsia para cultivo micológico cuyo informe fue Histoplasma capsulatum. Posteriormente evolucionó favorablemente, afebril y con parcial mejoría del estado general, sin embargo, el día 17/11/06 cursa con agitación, desaturación y un día después fallece por causa indeterminada. Se comenta este inhabitual caso nacional con algunos aportes epidemiológicos, de diagnóstico y sistemáticos.

\section{INTRODUCCION}

Histoplasma capsulatum var. capsulatum Darling, es uno de los hongos patógenos dimórficos mejor estudiados, cuya variación morfológica (hifas/levaduras) está fuertemente asociada a su estilo de vida y patogénesis. Este hongo cosmopolita tiene una mayor distribución en zonas

\begin{abstract}
A case of disseminated allocthonous histoplasmosis in a Colombian AIDS patient who came to the country in March 2006 is described. He consulted for a clinic syndrome which had started two months before and which was characterized by intense abdominal pain, vomits, weight loss, diaphoresis, evening fever, multiple adenopathies and oral candidosis. Among the exams he was submitted to it is noteworthy a thorax $X$-rays with interstitial infiltrate, pancitopenia, ELISA to detect positive VIH and negative microbiological cultures. The patient reacted unsatisfactorily in spite of the empirical, broad spectrum antimicrobian treatment; the cervical ganglion was byopsed revealing the presence of gemant yeasts in necrosis focuses after which a treatment with anfotericine $B$ was started, byopsia was repeated to get a mycological culture resulting Histoplasma capsulatum. Later on he reacted satisfactorily, he had no fever and showed a partial improvement in his general state, however on 11/17/06 he undergoes agitation, desaturation and he dies the following day due to an undetermined cause. This rarely frequent national case is commented together with the delivery of some epidemiological as well as diagnostic and systematic information.
\end{abstract}

templadas y tropicales, siendo endémico en NorteAmérica en el valle de Ohio, Mississippi (Rippon, 1988) y en algunos países de Centroamérica (Puerto Rico, El Salvador, Costa Rica, República Dominicana), SudAmérica (Venezuela, Ecuador, Brazil, Paraguay, Uruguay y Argentina, Fig. 1), Sudeste Asiático, Africa y Europa (Unis, et al.,2004; 


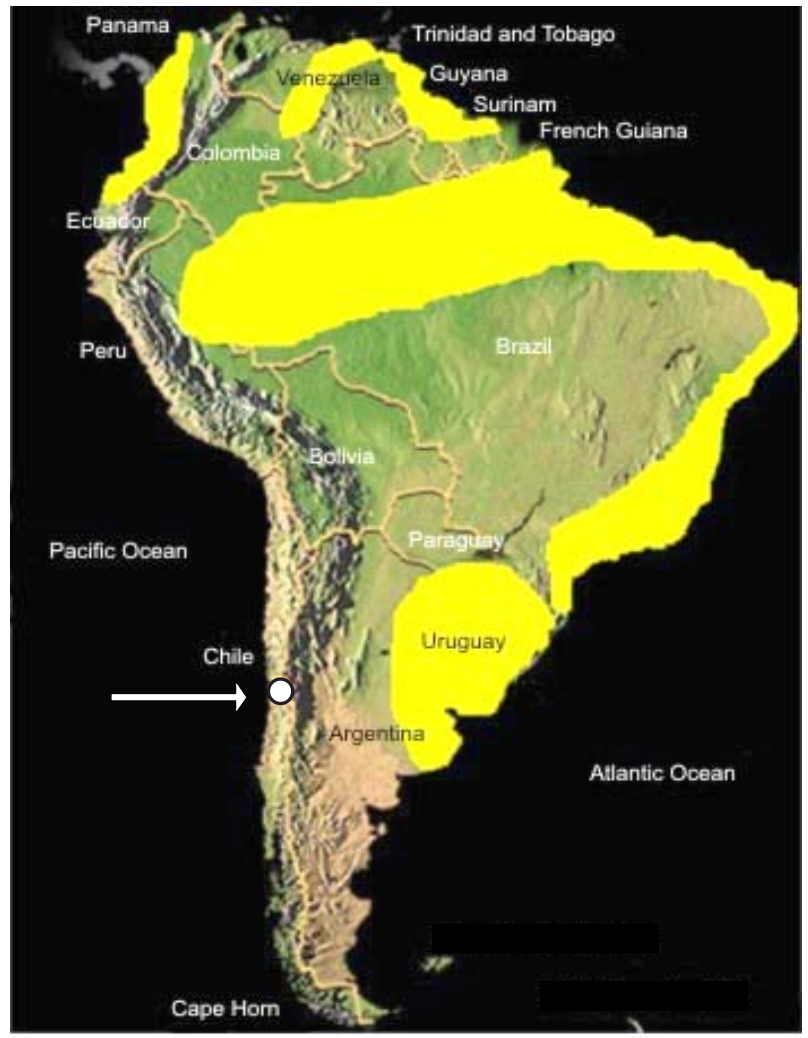

Figura 1. Distribución geográfica de la Histoplasmosis en Sud América (áreas claras). La flecha indica la ubicación de los 2 casos autóctonos nacionales (Modificado de Guimarães et al., 2006).

Caplivski et al.,2005; Guimarães et al.,2006). Las cepas de Centro América y Sud América pertenecen a otras poblaciones en base a sus de mtDNA (Vincent et al., 1986).Sus otras variedades son: H.capsulatum var. duboisii, descrito sólo en Africa y H.capsulatum var farciminosum, común en el Lejano Oeste y que produce linfangitis epizótica en caballos y mulas. El hábitat de la variedad capsulatum en su forma micelial $\left(20-30^{\circ} \mathrm{C}\right)$, son los suelos húmedos, ácidos y con alto contenido de nitrógeno; en especial, los excrementos de pájaros y murciélagos favorecen su crecimiento y esporulación (Lottenberg et al., 1979; KwonChung \& Bennet, 1992; Sutton et al., 1998).

La presencia autóctona de este agente en Chile parece ser rara, con sólo 2 casos en la literatura (Olivareas et al., 1952; Moyano et al., 1977), siendo la mayoría de los casos confirmados en personas que han viajado a zonas endémicas (turismo) expuestas a los ambientes donde la concentración del agente es alta ya sea en el suelo o en el aire, tales como: cuevas, galerías, minas subterráneas o los diversos lugares donde anidan murciélagos (McKinsey et al.,1997; Corbalán, 1970; Oddo \& Lobos,1988; Oddó, et al., 1983, 1990; Wolff, 1999; Cabello et al., 2002).

La histoplasmosis es considerada la más común de las micosis endémicas en pacientes con SIDA después de la criptococosis (McKinsey et al., 1997; Cahn, 2004) y el primer caso registrado en el país en un paciente con esta enfermedad fue en la década de los 90 (Pérez et al., 1993).

Nuestros objetivos se limitan a comentar, junto a los aspectos clínicos del caso, los actuales alcances ecológicos, patológicos, morfológicos y genéticos de este agente fúngico dimórfico.

\section{CASO CLINICO}

Paciente de 29 años, colombiano, heterosexual, con antecedentes de promiscuidad, que llega a Chile en Marzo del 2006. El 15/10/06 consulta en la Unidad de Emergencia del Hospital Carlos Van Buren de Valparaíso por un cuadro clínico de aproximadamente dos meses de evolución caracterizado por dolor abdominal intenso, vómitos a repetición, baja de peso de aproximadamente 20 kilos, diaforesis y fiebre de predominio vespertino. Se decide hospitalización para estudio, pero por falta de camas en dicho recinto se traslada al Hospital Eduardo Pereira de Valparaíso.

Dentro del exámen físico destacó la presencia de adenopatías cervicales, supraclaviculares e inguinales, candidosis oral y fistula anal. De los exámenes de laboratorio destacó un hematocrito de 26\%, leucocitos de 2300 células y 63000 plaquetas, además de una radiografía con infiltrado intersticial paracardíaco derecho (Fig. 2).

Posterior a su ingreso permanece febril $\left(38^{\circ} \mathrm{C}\right)$, soporoso, con desorientación temporoespacial, se mantiene la pancitopenia, VHS: 2.18, fosfatasa alcalina de 914, LDH en sangre de 1328, hemocultivos negativos, urocultivos negativos, monotest negativo, baciloscopía de expectoración negativa y VDRL en sangre negativo. La ecotomografía abdominal mostró hepatoesplenomegalia y ascitis en fosa iliaca derecha e hipogastrio, radiografía de tórax que mostró derrame pleural izquierdo, además de ELISA para VIH positivo. Se decide iniciar terapia con
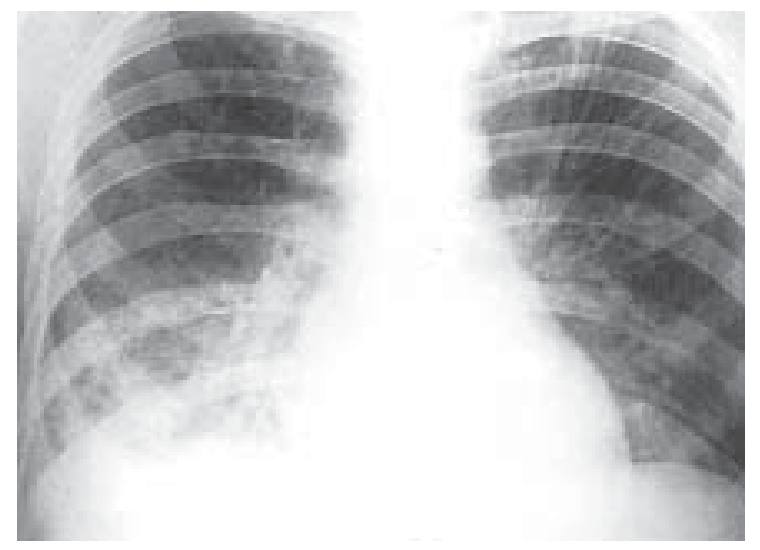

Figura 2.- Radiografía de tórax con infiltrado intersticial difuso con predominio paracardíaco derecho 

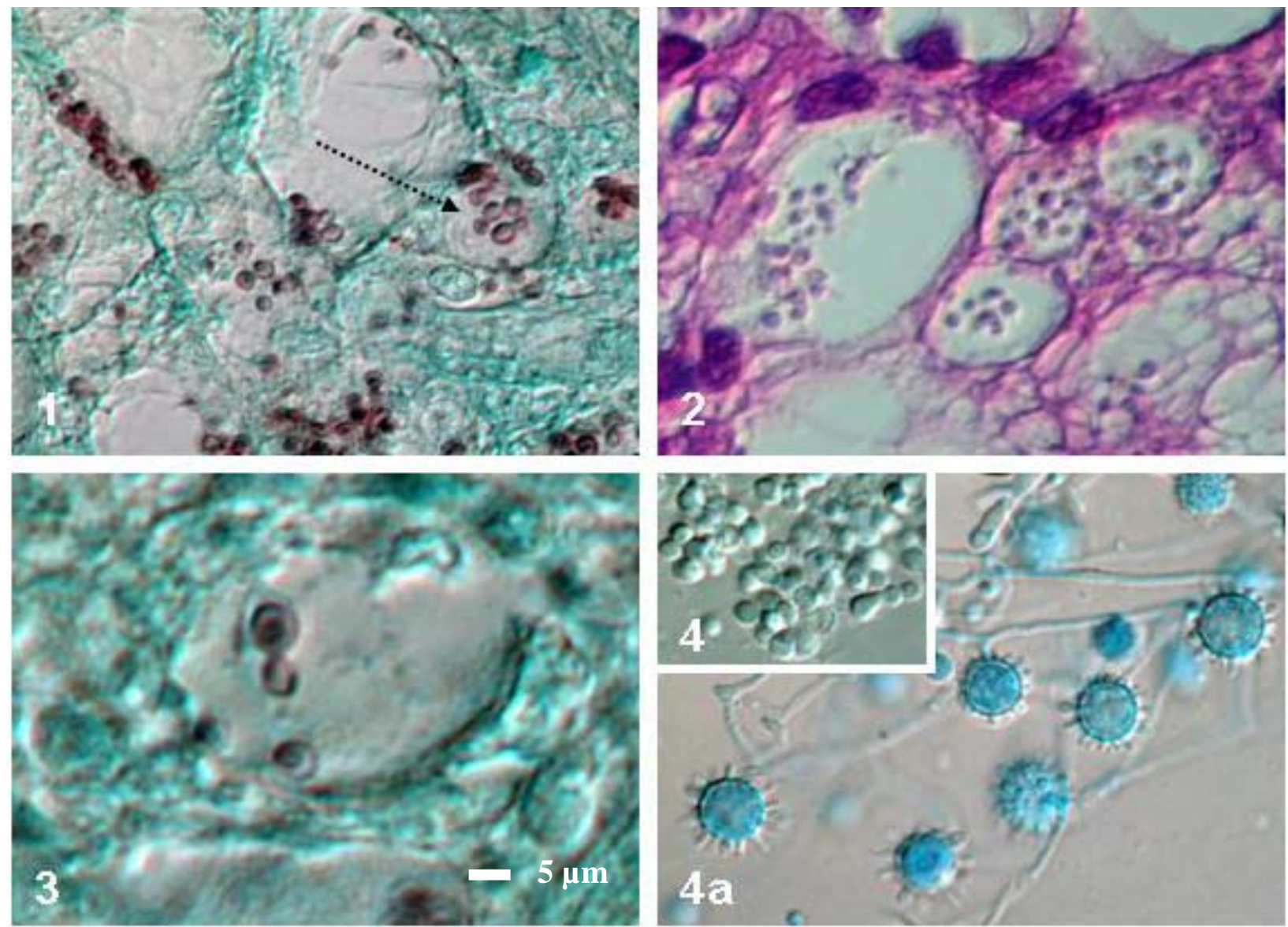

Figura 3. 1-4a , Histoplasma capsulatum var. capsulatum. 1. Levaduras gemando en foco de necrosis de ganglio cervical (Gomori Grocott) 1000X. 2. Levaduras gemando en foco de necrosis de ganglio cervical (Hematoxilina Eosina) 1000x. 3. Blastoconidio mostrando un halo claro citoplasmático simulando una cápsula (Gomori Grocott). 4. Fase levaduriforme en cultivo agar cerebro corazón + extracto de levadura a $37^{\circ} \mathrm{C}, 1000 x$. 4a. Macroconidios tuberculados en agar Sabouraud a $25^{\circ} \mathrm{C}, 1000 \mathrm{x}$.

cotrimoxazol, cefotaxima y clindamicina, además de biopsia de un ganglio cervical.

En los días siguientes evoluciona tórpidamente, con fiebre, taquicardia, disnea y alto requerimiento de oxígeno. El día 27/11/06, anatomía patológica informa la biopsia del ganglio cervical como: linfoadenitis necrotizante micótica por levaduras (Fig. 1-2-3), se tomó nueva muestra de ganglio y se envío al laboratorio de Micología de la Universidad de Valparaíso para identificación del agente. Se inicia tratamiento con anfotericina B por catéter venoso central a dosis de $1 \mathrm{mg} / \mathrm{K}$ al día y se mantuvo el tratamiento con cotrimoxazol, anti TBC empírico, cefotaxima y clindamicina endovenosa, además de azitromicina (1 g semanal).

Posteriormente el paciente evoluciona favorablente, cede la falla respiratoria y la fiebre, regresa parcialmente la pancitopenia y mejoran las pruebas hepáticas, por tal motivo se decide traslado al hospital Carlos Van Buren.

El 7/11/06, desde el laboratorio de Micología se informa del crecimiento de un hongo dimórfico correspon- diente a Histoplasma capsulatum; se decide continuar con anfotericina B y se suspende la clindamicina y el tratamiento anti TBC. Posteriormente continua su mejoría clínica, con Hto: 21\%, rcto. leuc.: 4200 celúlas y plaquetas: 111000 celúlas, por lo que fue transfundido con dos unidades de glóbulos rojos. El día 16/11/2006, completando 915 mg de anfotericina B, 23 días de cotrimoxazol y 20 días de cefotaxima, se decidió cambio a Itraconazol oral y se solicitó albendazol debido a informe coproparasitario de presencia de Strongyloides stercoralis.

El TAC de tórax y abdomen mostró infiltrados intersticiales bilaterales sugerentes de infección por germen atípico, además de atelectasia parcial del lóbulo inferior izquierdo, derrame pleural bilateral y cardiomegalia. En abdomen se observaron múltiples infartos en el bazo y colección subcapsular secundaria, leve hepatomegalia y moderada cantidad de líquido libre intraabdominal.

El día 17/11/06, cursa con agitación y desaturación, se indica hidrocortisona y haldol. El día 18/11/2006, a las 
07:00 am fallece; se solicita la autopsia, la cual es rechazada por los familiares, razón por la cual la causa de muerte queda indeterminada.

\section{COMENTARIOS GENERALES}

La esporádica presentación clínica de la histoplasmosis en Chile como de otros hongos dimórficos, constituye un problema de diagnóstico por la falta de experiencia de la comunidad médica y por presentar un cuadro clínico inespecífico similar a otras enfermedades infecciosas, especialmente en pacientes inmmunodeprimidos. A pesar de que nuestras barreras geográficas favorables impiden el asentamiento de la mayoría de los patógenos primarios fúngicos, la globalización industrial, el intercambio de productos alimenticios y las aberturas de las fronteras para un turismo masivo desde y hacia zonas endémicas, podría permitir pequeños asentamientos de algunos agentes fúngicos alóctonos en los diversos microclimas que posee Chile.

Si bien es cierto que la mayoría de los casos de histoplasmosis diagnosticados en Chile, provienen de países donde este agente es endémico o simplemente presente en algunos hábitat particulares, existen al parecer sólo 2 casos autóctonos descritos y la existencia de otros no ha sido diagnosticada o se encuentra en forma de literatura gris (no publicada o sólo presentada a congresos).

La existencia de muchas aves y en especial de murciélagos en nuestra región costera, con un clima templado cálido favorable al crecimiento de $\boldsymbol{H}$.capsulatum $\left(20-27^{\circ} \mathrm{C}\right)$, una alta humedad relativa por la presencia del mar y neblinas frecuentes en la costa, suelos ácidos por las plantaciones forestales de Pinus y Eucalyptus que rodean el litoral, son situaciones que podrían aportar las condiciones favorables a la adaptación de este hongo en los suelos.

\section{Obtención de las muestras}

Las muestras clínicas analizadas para el diagnóstico de H.capsulatum pueden ser muy variadas, desde aspirado bronquial, lavado broncoalveolar, esputo, orina, lesiones en piel y mucosas, biopsias de ganglios o de médula ósea. Estas 2 últimas como exámenes histopatológicos, se consideran un método rápido para el diagnóstico de histoplasmosis invasiva mediante el uso de tinciones de PAS y Grocott Metenamina plata (GMS) (Wheat, 2003). Los hemocultivos son también de utilidad con porcentajes de más de un $50 \%$ de positividad, principalmente en los pacientes con histoplasmosis crónica o diseminada, ya sea mediante lisis centrifugación modificada, la que resulta más efectiva que los cultivos bifásicos (Santiago et al., 2004). Actualmente las máquinas BACTEC permiten muy buena eficiencia en aislamientos de muchos tipos de especímenes bacterianos o fúngicos presentes en el torrente circulatorio.

La histopatología de un ganglio cervical fue en nuestro caso el primer aviso de esta micosis, la cual se ratificó posteriormente mediante el cultivo de otra biopsia en agar Sabouraud.

\section{Aspectos morfo-fisiológicos en cultivos}

H.capsulatum var. capsulatum, es un organismo dimórfico, filamentoso a temperaturas inferiores a $30^{\circ} \mathrm{C}$, pero en las células de los mamíferos o en medios especiales a $35-37^{\circ} \mathrm{C}$ crece como una pequeña levadura gemante.

En las zonas endémicas o no endémicas, donde la histoplasmosis es una enfermedad registrada esporádicamente, los métodos convencionales de identificación se basan aún en el aislamiento del agente desde muestras clínicas mediante el cultivo del especimen a $37^{\circ} \mathrm{C}$ durante 2 a 4 semanas; generalmente en medios enriquecidos usados en los laboratorioas de hospitales, como agar cerebro corazón, agar sangre o agar chocolate, que permiten el desarrollo de ambas fases, levaduriforme y filamentosa a distintas temperaturas. También puede usarse agar al $2 \%$ de glucosa $+1 \%$ de extracto de levadura, agar papa dextrosa + cisteína o en agar Sabouraud. Se conoce la lentitud de crecimiento de esta especie, situación que debe considerarse para no eliminar los cultivos antes de las 4-6 semanas. Deben efectuarse cultivos adicionales en los varios medios mencionados para obtener la morfología característica de las colonias y los patrones de esporulación que permitan demostrar las características macroconidias tuberculadas de la fase asexual de esta especie (Fig. 4a). H. capsulatum, no esporula bien en todos los cultivos, algunas cepas no lo hacen y un $10 \%$ produce sólo macroconidios de paredes lisas. Varias cepas no se convierten facilmente en levaduras en medios especiales enriquecidos con cisteína debido a sus características fisiológicas intrínsecas y son necesarios varios traspasos a intervalos de 3-5 días.(Eisemberg \& Goldman, 1991).

Debemos tener presente que en su fase levaduriforme este hongo presenta semejanzas con otras levaduras, especialmente en las preparaciones histológicas como en los cultivos, que pueden llevar a errores en el diagnóstico, principalmente con Candida glabrata, Penicillium marneffei, Pneumocystis jiroveci, Toxoplasma gondii y Cryptococcus neoformans . Por ende es necesario estar familiarizado con la morfología y el empleo de tinciones diferenciales (Guimarães et al., 2006).

Con respecto a su fase filamentosa, también pueden observarse similitudes con otros hongos anamórficos no relacionados, pero que presentan similar esporulación, como: Blastomyces dermatitidis, Renispora flavissima y algunas especies del género Sepedonium y Chrysos- 
porium (Kwon-Chung \& Bennet, 1992), incluyendo la reciente especie descrita en Francia bajo el nombre de Chrysosporium chiropterum Beguin \& Larcher (2004), aislada de excrementos de murciélagos y con una morfología similar a H.capsulatum. Se diferencia por su rápido crecimiento en cultivo, la producción de colonias rosadas a verdes, sin microconidios y no revierte a levadura a los $37^{\circ} \mathrm{C}$.

La morfología de nuestra cepa de $\boldsymbol{H}$. capsulatum var. capsulatum en cultivos enriquecidos como agar cerebro corazón + extracto de levadura, fue de lento crecimiento con colonias a los 12 días $\left(25^{\circ} \mathrm{C}\right)$ de color blanco a crema, lanosas a granulosas con reverso crema, cuyos diámetros no superaron los $11 \mathrm{~mm}$. Entre los 30$33^{\circ} \mathrm{C}$, midieron entre los 9 y $10 \mathrm{~mm}$ y a los $36-37^{\circ} \mathrm{C}$ no sobrepasaron los $6 \mathrm{~mm}$, adquiriendo un aspecto cremoso mucoide, de color blanco, que a la observación microscópica estaban integradas por levaduras gemando y algunas formas de transición especialmente en los bordes de las colonias (Fig.4). En agar Sabouraud glucosado con Caf.,el medio usado para la siembra directa de trozos del ganglio cervical del enfermo, se observó un crecimiento medianamente lento en los primeros 6 días de incubación a $37^{\circ} \mathrm{C}$ que alrededor de la muestra formaron colonias cremosas, pequeñas, de apecto mucoide. Al incubarse posteriormente a $25-27^{\circ} \mathrm{C}$, rápidamente tomaron un aspecto algodonoso a francamente granular (4 días), lo que permitió observar mediante preparaciones con lactofenol y azul de algodón, los típicos macroconidios tuberculados de 9 a $14 \mu \mathrm{m}$ (Fig. 4a), con proyecciones digitiformes en los de mayor tiempo de desarrollo. Estos aleuroconidios hialinos, de paredes gruesas, esféricos, terminales o laterales semejan clamidosporas. También observamos microconidios, subglobosos a ovoides 2-4 x 2,5-6 $\mu \mathrm{m}$, sésiles o sobre un corto pedicelo en hifas indiferenciadas.

En los cultivos viejos (+de 25 días) en agar Sabouraud, las colonias adquirieron tonalidades de color ante con reverso cafesoso.

Destacamos el rápido crecimiento y la capacidad de esporulación de los primeros cultivos de la cepa estudiada (10-12 días), que no presentó caracteres aberrantes como se describen algunos casos en la literatura (Lacaz, et al., 1999; Zuiani et al.,2006).

La diversidad feno y genotípica de $\boldsymbol{H}$. capsulatum var. capsulatum es otro aspecto ampliamente conocido (ver.Romero -Martínez et al., 2004), apoyando el concepto de que es una especie críptica o sea «un conjunto de especies» que se agrupan, pero con diferencias biológicas por su elevado polimorfismo genético (Kazuga et al., 1999).

La capacidad de recombinación entre las cepas de áreas endémicas (Indiana , USA) es otra característica de esta especie, originando nuevas subpoblaciones, pero sin evidencias de correlación entre un particular genotipo clonal, la severidad de la enfermedad o el estado inmmune del hospedador (Carter et al., 1996).

Algunas cepas de H.capsulatum difieren en su termotolerancia, en especial las cepas «Downs» (de bajo nivel de virulencia) que son más patógenas en hospederos con temperaturas corporales menores que $37^{\circ} \mathrm{C}$ y que se han aislado de pacientes con SIDA en USA (sin excluir que pueden infectarse también con las cepas tipo más comunes , G217 o G222B). Estas cepas de fenotipo Down, probablemente no producen infecciones sintomáticas en pacientes sanos (Spitzer et al., 1990).

\section{Diagnóstico no basado en cultivos}

El cultivo positivo obtenido de un paciente con histoplasmosis es una de las mejores evidencias de la enfermedad, sin embargo, en aquellos pacientes asintomáticos que presentan su forma leve, los cultivos son negativos. Debido a esto, en zonas endémicas, se han desarrollado técnicas rápidas, que mencionaremos brevemente, aunque muchas de ellas no pueden efectuarse por falta de reactivos, lo costoso de algunas metodologías y los esporádicos casos en las zonas no endémicas.

\section{1). Detección de anticuerpos.}

a). La fijación de complemento ya sea con el antígeno de la fase levaduriforme o la fase micelial tiene un $70-80 \%$ de especificidad. Títulos entre 1:8 y 1:16 son considerados positivos débiles e indican infección antigua, pero pueden observarse también en personas sanas que viven en zonas endémicas. Títulos superiores a 1:32 son indicativos de histoplasmosis activa (Bauman \& Smith, 1972; Kaufman et al., 1972).

b). La inmunodifusión, mide cuantitativamente los anticuerpos precipitantes (precipitina $\mathrm{H}$ y $\mathrm{M}$ ), es un método rápido, sencillo y efectivo, bastante común en los laboratorios en zonas endémicas, con una sensbilidad entre $70-100 \%$. La presencia de ambas bandas de precipitinas $\mathrm{H}$ y $\mathrm{M}$ es conclusiva para el diagnóstico de histoplasmosis (Johnson et al., 1984; Wheat, 2003).

c). La aglutinación del látex es una técnica con poca especificidad ya que algunos resultados falsos positivos se pueden dar en pacientes con tuberculosis y no discrimina bien entre anticuerpos de H.capsulatum y Blastomyces dermatitidis (Khansari et al., 1982).

d).Western blot y ELISA, ambas técnicas con buena sensibilidad y relativamente alta especificidad 70-95\% según la metodología empleada (como la de histoplasmina purificada y deglicolisada) y la evolución de la enfermedad (Zancope-Oliveira et al., 1994; Guimarães et al., 2004).

\section{2). Detección de antígenos.}

La detección de antígenos es más efectiva que la 
detección de anticuerpos en la histoplasmosis. Estos antígenos se encuentran en suero, orina, fluido pleural, lavado broncoalveolar, líquido cefaloraquídeo, etc. y son muy utiles en la enfermedad aguda, especialmente en los individuos con SIDA que no tienen generalmente anticuerpos detectables. Se puede emplear la detección del antígeno mediante anticuerpos fluorescentes en el esputo del paciente o en test inmunohistoquímicos. El radioinmuno ensayo es otra técnica para detectar antígenos (polisacárido) en suero y orina. La disminución de los títulos del antígeno se relacionan directamente con las condiciones clínicas del paciente y casos de falsos positivos pueden ocurrir en blastomycosis y paracoccidiomicosis (Wheat et al., 1992, 2002; Wheat, 2003).

3). Test cutáneos. Se emplean para evaluar la reactividad de los pacientes con histoplasmosis y son usados para estudios epidemiológicos en individuos que visitan zonas no endémicas o endémicas y durante las epidemias (Edwards \& Billings, 1971; Torres-Rodriguez et al., 1999).

En Chile estos test cutáneos se efectuaron en la década de 1950 por varios investigadores y permitieron establecer que los índices de sensibilización de la población chilena frente a la histoplasmina en la zona central, fueron muy bajos y varios de los casos positivos, también lo eran frente a la tuberculina (en : Piontelli,1982).

4). Exoantígenos. La presencia de antígenos únicos en los hongos permite identificaciones específicas mediante test de inmunodifusión y son de utilidad y gran sensibilidad para la identificación de las formas atípicas de $\boldsymbol{H}$. capsulatum, permitendo su separación de otros hongos saprófitos semejantes (Reiss et al., 2000).

5). Métodos moleculares. El diagnóstico molecular ha adquirido gran importancia por su rapidez y sensibilidad y es una herramienta adicional de diagnóstico especialmente en las zonas no endémicas.Existen diferentes técnicas de PCR y las más nueva de PCR anidada, puede detectar H.capsulatum en los tejidos, sangre, trozos de biopsia en parafina (procedimientos histopatológicos), tejidos en formalina, etc.(Bialek et al., 2001, 2002; Bracca, et al., 2003). En general, los centros hospitalarios nacionales no cuentan con sistemas de diagnóstico molecular específicos para esta micosis primaria.

\section{Aspectos filogenéticos.}

El primer caso autóctono de histoplasmosis (Olivarez et al., 1952), describe ampliamente los aspectos etilógicos, epidemiológicos y clínicos de la época, pero la literatura nacional posterior no comenta mayormente los aspectos sistemáticos y filogenéticos actualmente vigentes de $\boldsymbol{H}$. capsulatum y su fase sexual Ajellomyces capsulatum, por lo que consideramos aportar algunos comentarios.

Pertenece al Orden Onygenales (Ascomycota), con especies que presentan teleomorfos (fase sexual) con ascoma en gimnotecios o cleistotecios, ascos evanescentes, ascosporas unicelulares y anamorfos con aleuroconidios o artroconidios. Por tradición incluye 4 familias (Onigenaceae, Arthrodermataceae, Gymnoascaceae y Myxotrichaceae), que se separan en base a sus propiedades enzimáticas como el de degradar la celulosa o la queratina (Currah 1985, 1994). La última familia se ha excluido en la actualidad del Orden, por reconocerse más cercana a las Leotiales (Ascomycota)(Sugiyama et al.1999), pero el concepto de Onygenales se ha mantenido por los estudios ecológicos, morfológicos y moleculares en 2 de las familias. Sin embargo, la estructura filogenética de las Onygenaceae es polifilética según estudios recientes (Sugiyama \& Mikawa., 2001; Untereiner, et al., 2002), e incluye anamorfos de los géneros Blastomyces, Emmonsia, Histoplasma, Chrysosporium, Malbranchea y Paracoccidioides (los 3 primeros con teleomorfos en Ajellomyces). Posteriormente, Untereiner et al., 2004, con nuevos estudios moleculares, separaron una clade distinta dentro de las Onygenaceae, en especial la que incluye los patógenos dimórficos (Ajellomyces, Emmonsia y Paracoccidioides) y propusieron la nueva familia Ajellomycetaceae, cuyos miembros son saprófitos y patogénicos para los vertebrados y poseen ascomata globosos y apéndices espiralados, ascosporas globosas u obladas, ausencia de actividad queratinolítica, con anamorfos con conidios solitarios equinulados a tuberculados (H. capsulatum) o en artroconidios irregularmente alternados.

Al parecer Paracoccidioides brasiliensis, parece estar filogenéticamente relacionado con las especies de Ajellomyces, pero aún con posición incierta al igual que A. capsulatum (y su fase asexual o anamorfo Histoplasma capsulatum) que requieren mayores estudios (Untereiner et al., 2004).

\section{CONCLUSIONES}

La histoplasmosis diseminada, es una rara micosis en zonas no endémicas que afecta principalmente a pacientes inmunodeprimidos. De los 3 casos descritos en Chile, dos son autóctonos y uno alóctono (paciente con SIDA), además de otros sólo con compromiso pulmonar en pacientes inmunocompetentes que visitaron zonas endémicas. Por su escasa frecuencia clínica en nuestro ambiente, es probable que no se sospeche precozmente y se confunda con otras infecciones de similar sintomatología, tal como sucedió en nuestro caso. 
El desconocer que el paciente era portador de VIH SIDA, impidió la sospecha, su diagóstico precoz y por lo tanto un tratamiento oportuno. Se debe recordar que Hitoplasma capsulatum es un patógeno primario y no se deben manipular en el laboratorio sus cultivos si no se cuenta con medidas de seguridad biológicas clase II.

El constante flujo migratorio y turístico entre las zonas endémicas y nuestro país, nos obliga a pensar en histoplasmosis, por lo que además del cultivo y la histología, se podrían implementar algunas de las técnicas rápidas para su diagnóstico precoz.

\section{REFERENCIAS}

Bautman,D.S. \& Smith, C.D.(1976).Comparison of immunodiffusion and complement fixation test in the diagnosis of histoplasmosis. J. Clin. Microbiol. 2:77-80

Beguin,H.; Larcher, G.; Nolard, N. \& Chabasse, D. (2004). Chrysosporium chiropterum sp. nov., isolates in France resembling Chrysosporium state of Ajellomyces capsulatum (Histoplasma capsulatum) Medical Mycology 43:161-169

Bialek, R.; Fischer, J.; Feucth, A.; Najvar, L.K.; Dietz, K.; Knobolch, J.; Graybill, J.R.(2001). Diagnosis and monitoring of murine histoplasmosis by nested PCR assay. J. Clin. Microbiol. 39:1506-1509

Bialek, R.; Feucth, A.; Aepinus, C.;Just-Nubling, G.; Robertson, V.J.; Knobolch, J.; Hohle, R. (2002). Evaluation of two nested PCR assay for detection of Histoplasma capsulatum DNA in human tissue. J. Clin. Microbiol. 40:1644-1647

Bracca, A.; Tosello, M.E.;Girardini, J.E.; Amigot, S.L.; Gómez, C.; Serra, E. (2003). Molecular detection of Histoplasma capsulatum var. capsulatum in human clinical samples. J. Clin. Microbiol. 41:1753-1755

Cabello, H.A.; Manieu,D.M.; Noriega, M,R.;Mendoza, M.; Peralta,M.M.; Larraguibel, C.H. (2002). Histoplasmosis pulmonar. Rev. chil. infectol. 19:54-59

Cahan, P. (2004).Histoplasmosis en pacientes infectados por VIH en la era «HAART». Enf. Emerg. 6:5-7

Caplivski, D.; Salama, C.; Huppikar, S. \& Bottone, E.J. (2005). Disseminate histoplasmosis i five inmmunosuppressed patient: clinical, diagnostic and therapeutic perspective. Rev. Med. Microbiol. $16: 1-7$

Corvalán, G. (1970). Histoplasmosis pulmonar. Cartas a la redacción. Rev. Méd. Chile 80: 45-46

Currah, R.S.(1985). Taxonomy of the Onygenales: Arthrodermataceae, Gymnoascaceae, Myxotrichaceae, and Onygenaceae. Mycotaxon 14:1-216

Currah, R.S.(1994). Peridial morphology and evolution in the prototunicate ascomycetes. In:Hawskworth, D.L.(ed.) Ascomycete systematic:problems and perspectives in the ninties. N.York: Plenum Press. pp. 281-293

Edwards, P.Q. \& Billings, E.L. (1971). Worldwide pattern of skin sensitivity to histoplasmin. Am. J. Trop.Med. Hyg. 20:288-319

Eissenberg, L.G. \& Goldman, L.G. (1991). Histoplasma variation and adaptative starategies for parasitism: new perspective on histoplasmosis. Clin. Microbiol. Rev. 4:411-421

Guimaraes, A.J.; Pizzini, C.V.; De Matos Guedes, H.L.; Albuquerque, P.C.; Peralta, J.M.; Hamilton, A.J.; ZancopéOliveira, R.M. (2004). ELISA for early diagnosis of histoplasmosis. J. Med. Microbiol. 53:509-514

Guimaraes, A.J.; Nosanchuk, J.D.\& Zancopé-Oliveira, R.M. (2006). Diagnosis of Histoplasmosis.Braz.J.Microbiol. 37:1-13

Johnson, J.E.; Jeffery, B.\& Huppert, M. (1984). evaluation of five commercially available immunodiffusion kit for detection Coccidioides immitis and Histoplasma capsulatum antibodies. J. Clin. Microbiol. 20:530-532

Khansari, N.; Segre, D.\& Segre, M. (1982). Diagnosis of histoplasmosis and blastomycosis by antiglobulin hemagglutination test. Am.J. Vet. Res. 43:2279-2283

Kasuga, T.; Taylor, J.W. \& White, T.J. (1999). Phylogenetic relationships of varieties and geographical group of the human pathogenic fungus Histoplasma capsulatum Darling. J. Clin. Microbiol. 37:653-663

Kaufman, L.; Huppert, M.; Fava-Neto, C.; Negroni, R.; Restrepo.A. (1972).Manual os standarized serodiagnostic procedures for systemic mycosis. Part II: Complement fixation test. Panamerican Health organization.

Kwon-Chung, K.J. \& Bennet, J.E. (1992) Medical Mycology. Lea \& Febinger, Philadelphia.

Lacaz, C.D.; Del Negro, G.M.; Vidal, M.S.; Heins-Vaccari, E.M.; Santos, E.M.; Martins , M.A. et al. (1999). Atipical disseminate cutaneous histoplasmosis inan immunocompetent child, caused by aberrant variant of Histoplasma capsulatum var. capsulatum. Rev. Med. Trop. Sao Paulo 41:195-202

Lottenberg, R.; Waldman,R.H.; Ajello, L.; Hoff, G.L.; Bigler, W.; Zellner, S.R. (1979). Pulmonary Histoplasmosis associated with exploration of a bat cave. Am. J. Epidemiol.110:156-161

McKinsey, D.S.; Spiegel, R.A. Hutwagner, L. et al. (1997). Prospective study of histoplasmosis in patient infected with human immunodeficiency virus: incidence, risk factor, and pathophysiology. Clin. Inf. Dis. 24:1195-1203

Moyano,C.; Grispun,M.; Ferrada,L.; Paredes,L.; Iturriaga, M.; Mazzolotti, A. (1977). Histoplasma capsulatum. Rev Méd. Chile 105:902-904

Oddó, D.; Chuaqui, B. \& Cubillos, C.(1983). Histoplasmosis diseminada con examen ulktraestructural del hongo. Rev. Méd Chile 111:705-708

Oddó, D. \& Lobos, T. (1988). Micosis inhabituales en Chile: comunicación de 10 casos. Rev Méd. Chile. 116:1135-1142

Oddó, D.; Etchart,M. \& Thompson, L. (1990). Histoplasmosis dubosii (African histoplasmosis). An African case reported from Chile with ultraestructural study. Pathol. Res. Pract. 186:514-517 
Olivares, O.; Ahumada, J.; Vaccaro, U.; Paredes, L.; Pozo, S. (1952). Histoplasmosis generalizada: Primer caso autóctono en Chile.Aspectos clínicos e inmunobacteriológicos. Rev. Med. Chile 80:746-757

Piontelli, L.E. (1982) . Etapas evolutivas de la micología médica nacional: un nuevo y amplio capítulo de la micología chilena. Boletín Micológico 1:7-18

Reis, E.; Obayashi, T.; Orle, K.; Yoshida, M.; ZancopeOliveira, R.M. (2000). Non culture based diagnostic tests for mycotic infections. Med.Mycol. (Suppl.1). 38:147-199

Romero-Martínez, R.; Canteros, C. \& Taylor, M.L. (2004). Variabilidad cromosómica intraespecífica en hongos patógenos de humanos, especialmente en Histoplasma capsulatum. Rev. Iberoam. Micol. 21:168-176

Santiago, A.R.; Hernandez, B.; Rodríguez, M. \& Romero,H. (2004). Estudio comparativo de cultivos de sangre mediante métodos convencionales versus la técnica modificada de lisis/ centrifugación para el diagnóstico de fungemias. Rev. Iberoam. Micol. 21:198-201

Spitzar, E.D.; Keath, E.J.; Travis, S.J.; Painter, A.A.; Kobayashi, G.S.; Medoff, G. (1990). Temperature sensitive variants of Histoplasma capsulatum isolated from patient with acquired immunodeficiency syndrome. J. Inf. Dis. 162:258-261

Sugiyama,M.; Ohara, S. \& Mikawa, T. (1999). Molecular Phylogeny of onygelen fungi based on small subunit ribosomal DNA (SSU rDNA) sequenced. Mycoscience 40:251-258

Sugiyama, M. \& Mikawa, T. (2001).Phylogenetic analysis of the non-pathogenic genus Spiromastix (Onygenaceae) and related onyhenalean fungi based on large subunit ribosomal DNA sequences. Mycosciences 42:413-421

Sutton, D.A.; Fothergill, A.W. \& Rinaldi, M.G. eds.(1998). Guide to clinically significant fungi. Williams \& Wilkins, Baltimore

Torres-Rodriguez, J.M.; Ribas-Forcadell, E.; Gascon, J.; Espasa, M. (1999). Valor diagnóstico de la intradermoreacción con histoplasmina en áreas no endémicas de histoplasmosis. Med. Clin. (Barcelona). 113:37-38

Unis, G.; Oliveira, F.de M.\& Severo, L.C. (2004). Histoplasmosis disseminadano Rio Grande do Sul. Rev Soc. Braz. Med. Trop. 37:463-468

Untereiner, W.A.; Scott. J.A.; Naveau, R.S.; Currah, R.S.; Bachewich, J.(2002). Phylogeny of Ajellomyces, Polytolypa and Spiromastix (Onygenaceae) inferred from rDNAsequences an nonmolecular data. Stud. Mycvol. 47:25-35

Vincent, R.D.; Goewert, R.; Goldman,W.E.; Kobayashi, G.S.; Lambowitz, A.M.; Medoff, G. (1986). Classification of Histoplasma capsulatum isolates by restriction fragment polymorphisms. J. Bac. 165:813-818

Wheat, J.L.; Garringer, T.; Brizendine, E.\& Connoly, K. (2002). Diagnosis of histoplasmosis by antigen detection based upon experience at the histoplasmosis reference laboratory. Diagn. Microbiol. Infect. Dis. 43:29-37

Wheat, J.L.; Cannoly-Stringfield, P.; Williams, B.; Connoly, K.; Blair, R.; Bartiett, M. (1992).Diagnosis of histoplasmosis in patients with the acquired immunodeficiency syndrome by detection of Histoplasma capsulatum polisaccharide antigen in bronchoalveolar lavage fulid. Am. Rev. Respir. Dis. 145:1421-1424

Wheat, J.L (2003).Current diagnosis of histoplasmosis. Trends Microbiol. 11:488-494

Wolff, M.S.(1999). Brote de histoplasmosis aguda en viajeros chilenos a la selva ecuatoriana:un ejemplo de medicina geográfica. Rev. Méd. Chile 127:1359-1364.

Zancope-Oliveira, R.M.; Bragg, S.L.; Reiss, E.; Wanke, B.; Peralta, J.M.(1994).Effects of histoplasmin M antigen chemical and enzymatic chemical deglycosylation ol cross- reactivity in the enzyme-linked immunoelectrotransfer blot method. Clin. Diagn. Lab. Immunol. 1:390-393

Zuiani, M.F.; Rivas, M.C.; Lee, W.; Guelfand, L.; Davel, G.; Canteros, C.E. (2006). Aislamiento de Histoplasma capsulatum con morfología aberrante obtenidos en la República Argentina. Rev. Argen. Micol.38:79-83 